\title{
Induction of Preadipocyte Differentiation by Mature Fat Cells in the Rat
}

\author{
G. Shillabeer, J. M. Forden, and D. C. W. Lau \\ Department of Medicine and Julia McFarlane Diabetes Research Centre, The University of Calgary, Calgary, Alberta, Canada T2N 4NI
}

\begin{abstract}
In this study we investigated the influence of mature adipocytes, derived from rat adipose tissue, on the replication and differentiation of preadipocytes in primary culture. Mature fat did not inhibit preadipocyte replication within the 6-d period studied. Preadipocyte differentiation, as assessed by both cytoplasmic lipid accretion and an increase in glycerophosphate dehydrogenase (GPDH) activity, was significantly stimulated by the presence of mature fat tissue or isolated adipocytes. The proportion of cells containing visible lipid droplets by oil red $O$ staining was $47 \pm 10$ to $58 \pm 10 \%$ (depending on the site of origin of the preadipocytes) when cocultured with mature fat compared with $<1$ to $2 \pm 1 \%$ when cultured in medium alone, while GPDH activity was $344 \pm 9$ compared with $43 \pm 3$ nM NADH/ min per mg protein, respectively. This effect was not due to release of triacylglycerols from damaged adipocytes. Fatty acids added to the medium promoted lipid accumulation but did not stimulate a rise in GPDH activity. We concluded that mature adipocytes may release factor(s) that promote preadipocyte differentiation (and maturation).
\end{abstract}

\section{Introduction}

Established adipogenic cell lines have been used extensively to investigate the regulation of cell proliferation and differentiation $^{1}$ in culture $(1,2)$. Adipogenesis is initiated in cell lines, such as murine 3T3-L1 cells, in response to insulin, insulinlike growth factor I, growth hormone, corticosteroids, thyroid hormone, and factors other than growth hormone in human plasma (3-7). The emergence of the lipogenic enzymes lipoprotein lipase (8-10) and glycerophosphate dehydrogenase $(\mathrm{GPDH})^{2}(11)$ as early and late markers of adipose conversion, respectively, is followed by the accumulation of fat droplets within the cell which continues until the characteristic morphology of the mature adipocyte is attained.

Address correspondence to Dr. David C. W. Lau, Room 2953, Health Sciences Centre, 3330 Hospital Drive NW, Calgary, Alberta, Canada T2N 4N1.

Received for publication 20 October 1988 and in revised form 9 February 1989.

1. In this paper we have used the terms differentiation and adipose conversion interchangeably. However, the processes involved in the transformation of 3T 3 cells and preadipocytes from the stromal vascular fraction of adipose tissue into mature fat cells may not be the same. 2. Abbreviations used in this paper: GPDH, glycerophosphate dehydrogenase; MIX, differentiation mix; TG, triacylglycerols.

J. Clin. Invest.

(c) The American Society for Clinical Investigation, Inc.

0021-9738/89/08/0381/07 \$2.00

Volume 84, August 1989, 381-387
The control of adipose conversion in vivo may, however, be more complex and subject to many diverse regulatory factors. The differentiation of preadipocytes, originating from the stromal vascular fraction of adipose tissue, to mature fat cells follows a similar course in vitro to that of the 3T3-L1 cells, but apparently requires only insulin and glucocorticoids (12).

Regional variations in the growth of adipose tissue in vivo (13) and in vitro $(14,15)$ suggest that local factors may be involved in the control of adipose tissue growth. For example, both preadipocytes and microvascular endothelial cells derived from the retroperitoneal site demonstrate exaggerated replication in culture $(14,15)$. Preadipocytes in vivo are exposed not only to circulating hormones and factors yet to be identified, but to different cell types within adipose tissue and fluctuating substrate and metabolite concentrations. We have previously demonstrated that microvascular endothelial cells, isolated from rat adipose tissue, released a mitogenic factor into the medium which stimulated the rate of replication of preadipocytes in culture $(15,16)$. Furthermore, preadipocytes from the massively obese human released factors mitogenic on rat preadipocytes (17). These mitogens are proteins that are heat and trypsin sensitive. The above observations led us to hypothesize that the various cell strains within adipose tissue may act via paracrine mechanisms to regulate preadipocyte replication and differentiation and that this may vary with the site of origin of the adipose tissue. In the present study we have investigated the effect of mature fat cells on the rate of differentiation and replication of preadipocytes, derived from three different fat depots, in primary culture.

\section{Methods}

Male Sprague-Dawley rats (Charles River Breeding Laboratories Inc., Wilmington, MA) weighing $580-780 \mathrm{~g}$ (donor rats) were killed by exsanguination under light ether anesthesia. Epididymal, retroperitoneal, and inguinal fat pads were excised aseptically. One of each pair of fat pads was finely chopped and kept until used in Alpha MEM (Gibco Laboratories, Burlington, ON) supplemented with 5\% calf serum (Bocknek, BDH, Toronto, ON) and 5\% fetal bovine serum (HyClone, Logan, UT) containing penicillin $\left(1.7 \times 10^{-4} \mathrm{M}\right)$ and streptomycin $\left(9.2 \times 10^{-5} \mathrm{M}\right)$. Alternatively, free mature fat cells were isolated from the fat pads by digestion with collagenase $(2 \mathrm{mg} / \mathrm{ml}$; type IV; Sigma Chemical Co., St. Louis, MO) in HBSS (Gibco Laboratories) and $5 \% \mathrm{BSA}$ with gentle shaking at $37^{\circ} \mathrm{C}$ for $30 \mathrm{~min}$. Aliquots of the floating adipocyte layer were used immediately as described below.

Preadipocytes were isolated from the other fat pad of each pair as previously described (1). After collagenase digestion $(2 \mathrm{mg} / \mathrm{ml})$ for 45 min at $37^{\circ} \mathrm{C}$ with shaking, the cell suspension was filtered through a 250- $\mu \mathrm{m}$ mesh nitex filter (B \& SH Thompson \& Co. Ltd., Scarborough, $\mathrm{ON}$ ) and then centrifuged. The pellet was resuspended and filtered through a $25-\mu \mathrm{m}$ mesh filter and centrifuged again. The pellet obtained consisted mainly of preadipocytes. Cells were enumerated using a Coulter counter (Coulter Electronics Inc., Hialeah, FL) and seeded at an approximate density of $1 \times 10^{4} / \mathrm{cm}^{2}$ in Alpha MEM supplemented as above. Cultures were maintained at $37^{\circ} \mathrm{C}$ in a humidified atmosphere of $95 \%$ air- $5 \% \mathrm{CO}_{2}$. 
Preadipocytes derived by the same methods from the fat pads of younger male Sprague-Dawley rats $(400-550 \mathrm{~g})$ were used as test cells in the assays to be described below.

Assay of preadipocyte differentiation. Preadipocytes from donor rats were seeded in $35-\mathrm{mm}$ well plates and grown under four conditions: $(a)$ cells alone (control); $(b)$ cells with $\sim 50 \mathrm{mg}$ finely chopped fat tissue from the same region of origin (i.e., epididymal preadipocytes plus epididymal fat); $(c)$ cells with $50 \mu \mathrm{l}$ mixed triacylglycerols (TG; safflower oil) added to the medium as a control for the effect of free fat released as a result of tissue damage in condition $(b)$; and $(d)$ cells grown in Alpha MEM alone for $5 \mathrm{~d}$ until confluent, at which time the medium was replaced with fresh Alpha MEM supplemented with $10^{-8}$ $\mathrm{M}$ insulin, $10^{-7} \mathrm{M}$ corticosterone, and $0.5 \mathrm{mM}$ 1-methyl-3-isobutylxanthine. After $48 \mathrm{~h}$ this medium was replaced with fresh Alpha MEM containing, in addition to the supplements described above, $10^{-8} \mathrm{M}$ insulin, $10^{-7} \mathrm{M}$ corticosterone, and $0.5 \%$ (vol/vol) intralipid (KabiVitrum, Dorval, PQ) (18). The culture conditions described under $(d)$ are referred to collectively below as differentiation mix (MIX).

Preadipocytes from test rats were treated in the same manner as the donor cells except that under condition $(b)$ mature fat tissue from the donor rats was added to cultures of test preadipocytes. In addition to the above, test rat preadipocytes were exposed to three further conditions: $(e)$ cells with oleic acid (range, $0.1-5.0 \mathrm{mM}$ final concentration in medium; the free fatty acid was shaken with fetal bovine serum before addition to the Alpha MEM); $(f)$ cells with $\sim 10 \mathrm{mg}$ rat skeletal muscle tissue; or $(g)$ cells with sodium lactate $(2$ or $6 \mathrm{mM}$ final concentration in medium). The effectiveness of isolated mature fat cells compared with that of mature fat tissue on differentiation was also tested to control for the presence of other cell types in the tissue.

To eliminate any effect due to cellular contact between the chopped mature fat tissue and preadipocytes in condition $(b)$, the mature fat in some cases was placed in culture well inserts $(30-\mathrm{mm}$ Millicell-CM, 0.4- $\mu \mathrm{m}$ membrane pore size; Millipore/Continental Water Systems, Bedford, MA).

After $5 \mathrm{~d}$ cells under all conditions except condition $(d)$ were fixed in $10 \%$ formalin, stained with oil red $\mathrm{O}$ to show neutral lipid droplets, and counterstained with $10 \%$ Giemsa. Cells grown under condition $(d)$ were fixed and stained in the same manner after the additional $7 \mathrm{~d}$ of culture with the differentiation mixture. Morphological assessment of differentiation was quantitated microscopically by enumerating cells containing visible fat droplets, and the results were expressed as a percentage of the total number of cells in eight randomly selected fields.

GPDH (EC 1.1.1.8) assay. An increase in GPDH activity is a late marker of adipose differentiation (11). To establish that the presence of lipid droplets within the preadipocytes was due to differentiation rather than the simple uptake of lipid from the medium (19), GPDH activity was assayed according to the method of Wise and Green (20).

Preadipocytes derived from the retroperitoneal fat pads of the test rats were cultured in flasks $\left(75 \mathrm{~cm}^{2}\right)$ at a seeding density of $1 \times 10^{4}$ cells $/ \mathrm{cm}^{2}$ and exposed to differentiation conditions $(a-d)$ described above. Cells in second or third subcultures were used as baseline (no visible differentiation) since a small percentage of preadipocytes in primary culture showed spontaneous accumulation of lipid within the $5 \mathrm{~d}$ of culture. Instead of fixing and staining the cells at the appropriate time intervals, the cells were washed in PBS, harvested with a rubber scraper, and stored at $-85^{\circ} \mathrm{C}$ until used.

Cells were homogenized in $50 \mathrm{mM}$ Tris- $\mathrm{HCl}$ buffer (containing 1 mM EDTA and $1 \mathrm{mM}$ mercaptoethanol, $\mathrm{pH}$ 7.5) and centrifuged at $100,000 \mathrm{~g}$ for $1 \mathrm{~h}$ at $4^{\circ} \mathrm{C}$. GPDH activity was determined under zero order kinetics and optimal substrate and cofactor conditions (20). The substrate, dihydroxyacetone phosphate, was added to aliquots of the infranatant fraction of the tissue homogenate in the presence of $\mathrm{NADH}$. The change in absorbance at $340 \mathrm{~nm}$ due to oxidation of NADH was followed with a Gilford response spectrophotometer at $23^{\circ} \mathrm{C}$. $1 \mathrm{U}$ of enzyme activity corresponded to the oxidation of $1 \mathrm{nmol}$ of $\mathrm{NADH} / \mathrm{min}$. The protein content of the homogenate was determined by the Coomassie blue method (21).

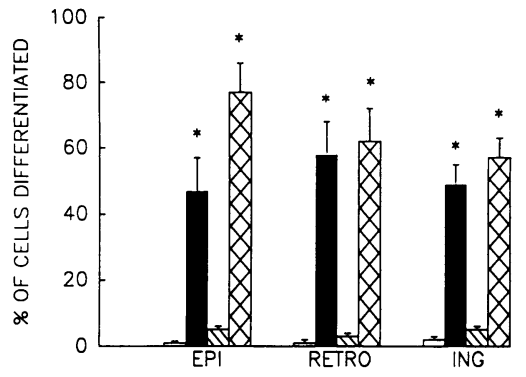

Figure 1. Induction of preadipocyte differentiation by mature fat. The number of cells containing visible lipid droplets by oil red $\mathrm{O}$ staining is shown as a percentage of the total cells counted (means \pm SEM). Preadipocytes derived from epididymal $(E P I)$, retroperitoneal $(R E T R O)$, and inguinal (ING) fat pads were grown in Alpha MEM alone (open bars), with the addition of mature fat tissue (solid bars) or TG (hatched bars), or with MIX (cross-hatched bars). The conditions are described in the text. *Values significantly different from control and $+\mathrm{TG}, P<0.001$.

The concentration of lactate in medium in which cells were cultured under conditions $(a),(b)$, or $(g)$ was determined enzymatically at day 5 using a modification of the method of Marbach and Weil (LA pack for the Automatic Clinical Analyzer III; Du Pont Instruments, Wilmington, DE) (22).

Assay of preadipocyte proliferation. Since arrest of growth has been associated with differentiation (23-25), a change in the rate of differentiation might be associated with a change in rate of growth. We therefore measured the rate of proliferation of preadipocytes under the same conditions used to determine the capacity of mature fat tissue to induce differentiation.

Preadipocytes from both donor and test rats were seeded in 24-well plates under three conditions: $(a)$ cells without addition (control); $(b)$ cells with $10 \mu \mathrm{l}$ mixed TG added to the medium; and (c) cells with $\sim 10 \mathrm{mg}$ chopped fat tissue from the same region of origin (i.e., epididymal preadipocytes plus epididymal fat). The rate of replication was measured by cell enumeration on successive days in duplicate wells, cultured under each condition, after trypsinization using a Coulter counter.

Data analysis. All data were analyzed by analysis of variance, Tukey's method for multiple comparisons, and, where appropriate, $t$ tests for paired and unpaired data.

\section{Results}

Assay of preadipocyte differentiation. Preadipocytes from all three fat tissue regions that were cultured in the presence of

Table I. Effect of Mature Fat on Preadipocyte GPDH Specific Activity

\begin{tabular}{lcc}
\hline \multicolumn{1}{c}{ Conditions } & GPDH specific activity & $n$ \\
\hline & $n M N A D H /$ min per $m$ m protein & \\
Baseline & $4.1 \pm 1.2$ & 4 \\
Control & $43.1 \pm 3.1^{*}$ & 4 \\
+MFAT & $344.3 \pm 8.9^{\ddagger}$ & 6 \\
+TG & $43.2 \pm 10.6^{*}$ & 6 \\
+MIX & $416.9 \pm 33.8^{\ddagger}$ & 6 \\
+Oleic acid & $46.7 \pm 36.0^{*}$ & 4 \\
\hline
\end{tabular}

Baseline denotes preadipocytes derived from donor rats from 2 nd to 4th subcultures; +oleic acid, cells grown in primary culture in the presence of $1 \mathrm{mM}$ oleic acid; other conditions were as described in Fig. 1. Sample size is given in the column under $n$.

* Values significantly different from baseline, $P<0.05$.

₹Values significantly different from baseline, control, and +oleic acid, $P<0.05$. 

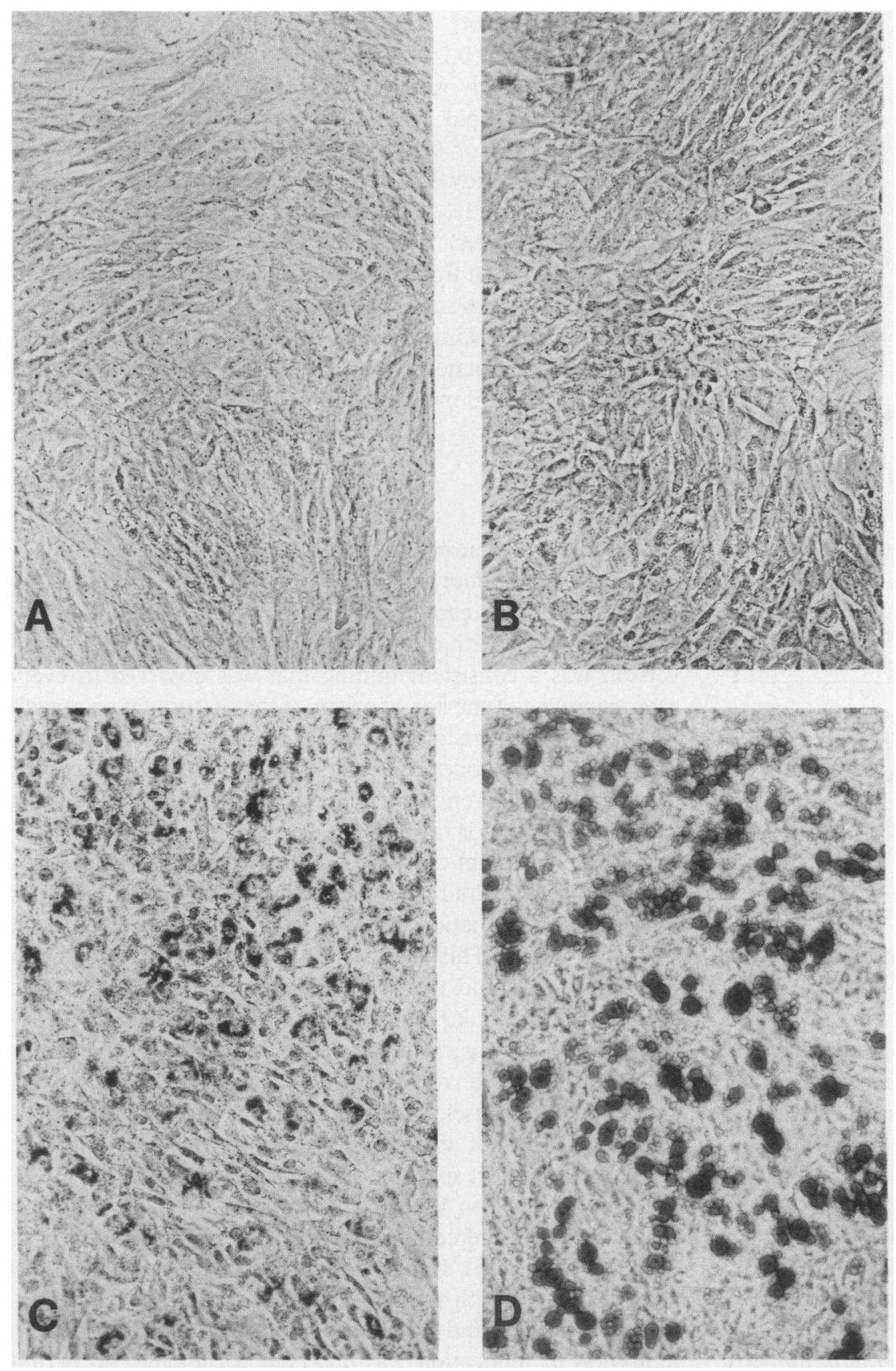

Figure 2. Photomicrographs of inguinal preadipocytes showing cytoplasmic lipid inclusions. Cells were fixed, stained with oil red $\mathrm{O}$ for neutral lipid, and counterstained with Giemsa. Cells were cultured for $5 \mathrm{~d}$ in Alpha MEM alone $(A)$ or with addition of TG $(B)$, mature fat tissue $(C)$, or MIX $(D)$. The oil red O-stained lipid droplets appear dark. Original magnification, $\times 200$. mature fat tissue showed a 30-40-fold increase in the accumulation of lipid droplets compared with cells that were cultured in Alpha MEM alone or in medium supplemented with TG (Fig. 1). An increase in GPDH activity in cells incubated with mature fat tissue paralleled the morphological appearance of the lipid droplets (Table I). When adipose conversion was induced by the addition of MIX, the proportion of preadipocytes containing lipid droplets was not significantly different from those cultured with mature fat tissue (Fig. 1), but the size of the droplets was much larger, indicating greater cytoplasmic lipid accretion (Fig. 2). This apparently more advanced stage of differentiation was not reflected, however, by a significant elevation of GPDH activity in cells exposed to MIX compared with that in cells cultured with mature fat (Table I).

The effect of mature fat tissue on lipid accumulation by preadipocytes derived from test rats was not different from the effect on the donor cells (Table II). Cytoplasmic lipid inclusions were observed in preadipocytes incubated with mature fat tissue or cells well before confluence was attained (Fig. $3 \mathrm{~B}$ ). Similar results were obtained when the mature fat tissue was separated from the cocultured preadipocytes by use of culture well inserts. The percentage of cells showing lipid accumulation was $30 \pm 4(n=7), 52 \pm 14(n=6)$, and $39 \pm 8 \%(n=7)$ with inserts, and $49 \pm 5(n=33), 59 \pm 5(n=31)$, and $50 \pm 4 \%(n=35)$ without inserts for epididymal, retroperitoneal, and inguinal preadipocytes, respectively.

Preadipocytes from all three fat tissue regions grown in the presence of isolated mature fat cells showed a similar accumulation of lipid droplets $(35 \pm 2 \%$, mean \pm SEM, $n=6)$ to those grown with mature fat tissue.

Assay of preadipocyte proliferation. The presence of mature fat tissue or TG did not affect the rate of replication of 
Table II. Preadipocyte Differentiation: Comparison of Donor and Recipient Preadipocytes

\begin{tabular}{cccc}
\hline Condition & Donor & Test & $n$ \\
\hline & & $\%$ & \\
Epididymal & & & \\
Control & $<1$ & $<1$ & 9 \\
+MFAT & $47 \pm 10^{* \neq}$ & $54 \pm 11^{* \ddagger}$ & 9 \\
+TG & $5 \pm 1^{*}$ & $6 \pm 3$ & 8 \\
+MIX & $77 \pm 9^{* \neq}$ & $75 \pm 9^{*}$ & 6 \\
Retroperitoneal & & & \\
Control & $1 \pm 1$ & $2 \pm 1$ & 9 \\
+MFAT & $58 \pm 10^{* \ddagger}$ & $52 \pm 10^{* \ddagger}$ & 9 \\
+TG & $3 \pm 1$ & $9 \pm 3$ & 9 \\
+MIX & $62 \pm 10^{* \ddagger}$ & $62 \pm 5^{* \ddagger}$ & 7 \\
Inguinal & & & \\
Control & $2 \pm 1$ & $2 \pm 1$ & 9 \\
+MFAT & $49 \pm 6^{* \ddagger}$ & $49 \pm 9$ & 9 \\
+ TG & $5 \pm 1$ & $7 \pm 2^{*}$ & 9 \\
+MIX & $57 \pm 6$ & $52 \pm 5^{* \ddagger}$ & 7 \\
& & & \\
\hline
\end{tabular}

Abbreviations are the same as those in Fig. 1. Mature adipocytes and preadipocytes were obtained from either donor or test rats. The three adipose tissue regions studied were epididymal, retroperitoneal, and inguinal.

* Values significantly different from control, $P<0.05$.

₹ Values significantly different from TG, $P<0.05$.

epididymal, retroperitoneal, or inguinal preadipocytes from test or donor rats compared with controls over the 6-d period tested (Fig. 4).

Effect of skeletal muscle tissue on preadipocyte replication and differentiation. Growth of preadipocytes was inhibited by the presence of skeletal muscle tissue $(10-20 \mathrm{mg})$. While the rate of replication of these cultures was not measured, the number of cells in each microscopic field assessed for differentiation was reduced by $80-90 \%$ compared with those of cells grown with mature fat tissue. When the amount of cocultured muscle tissue was reduced sufficiently to prevent inhibition of replication, lipid accumulation was not different from control ( $7 \pm 2 \%$ with muscle vs. $6 \pm 1 \%$ for control, $n=6$ ).

Effect of oleic acid on replication and differentiation. All concentrations of oleic acid of $1 \mathrm{mM}$ or more inhibited cell replication (number of cells counted/microscopic field for cultures with $1 \mathrm{mM}$ oleic acid was $71 \pm 29$ vs. $292 \pm 20$ for control, $n=6$ ) and rapidly induced accumulation of cytoplasmic lipid droplets in almost every cell. By the fifth day of culture few cells remained attached to the culture dish and most of the detached cells were found to have lysed. Despite the inhibition of cell replication in these cultures, dividing cells containing lipid droplets were observed (Fig. $3 A$ ). Lower concentrations (0.1-0.25 mM) of fatty acid did not inhibit replication (number of cells counted/field for cultures with $0.5 \mathrm{mM}, 0.25 \mathrm{mM}$, and $0.1 \mathrm{mM}$ oleic acid were $296 \pm 20,292 \pm 16$, and $309 \pm 10$, respectively, vs. $292 \pm 20$ for control, $n=6$ ). Most cells showed the accumulation of multiple small lipid droplets, although at the lowest concentration $(0.1 \mathrm{mM})$ some cells contained droplets smaller than those considered acceptable for counting under conditions $(a-d)$. The percentages of cells showing admissible lipid accumulation in cultures exposed to fatty acid were $100 \%$ (10 mM), 100\% (5 mM), 100\% (1 mM), $98 \pm 1 \%$ $(0.5 \mathrm{mM}), 96 \pm 1 \%(0.25 \mathrm{mM})$, and $74 \pm 6 \%(0.1 \mathrm{mM})$.

Effect of lactate on differentiation. There was no visible accumulation of lipid droplets in preadipocytes incubated in the presence of 2 or $6 \mathrm{mM}$ lactate, whereas those grown in medium alone showed some spontaneous differentiation $(1 \pm 1,3 \pm 1$, and $1 \pm 1 \%$ of epididymal, retroperitoneal, and inguinal preadipocytes). The final concentrations of lactate in medium withdrawn from cells cultured under control $(a)$ and + MFAT $(b)$ conditions at day 5 were $3.0 \pm 0.1$ and $3.8 \pm 0.5$ $\mathrm{mM}$, respectively, while those in medium from cells grown in the presence of lactate $(g)$ were $6.3 \pm 0.1 \mathrm{mM}(2 \mathrm{mM}$ lactate) and $9.4 \pm 0.2 \mathrm{mM}$ (6 mM lactate).

\section{Discussion}

In this study we demonstrated mature fat-induced differentiation as quantified morphologically by cytoplasmic lipid accretion and by an increase in GPDH activity. The induction was rapid, occurring within $5 \mathrm{~d}$ of seeding the cells. Adipose conversion was a consistent finding that was observed in every case regardless of the site of origin of the mature fat or preadipocytes. The mature fat was equally as effective on test preadipocytes as on the donor cells, implying that the influence of the mature fat on differentiation was not due to prior conditioning specific to the donor rats.

When mature fat cells were isolated from fat tissue by collagenase digestion and incubated with preadipocytes, a similar degree of differentiation was obtained as with incubation of the whole tissue. This suggests that the effect was specific to mature fat cells and was not dependent on other cell types, such as microvascular endothelial cells within the tissue. Preliminary studies suggested that the endothelial cells only stimulated preadipocyte replication but not differentiation (16). Coculture with muscle tissue (in amounts that did not inhibit replication) did not affect lipid accretion, which supports the concept of an effect specific to mature fat cells.

Growth arrest in the $G_{1}$ phase of the cell cycle has been reported to be a prerequisite for the onset of differentiation of 3T3-T cells (23-25). In addition, terminal differentiation has been associated with the irreversible loss of proliferative potential of 3T3-T and other cell lines (26). In our study no inhibition of replication was observed within the 5-d period during which differentiation was induced (Fig. 2). There are several possible interpretations of the continuation of the replicative ability of the preadipocytes in the presence of mature fat tissue. Preadipocytes from the stromal vascular fraction of fat tissue in primary culture may differ from adipogenic clonal cell lines in that growth arrest may not be a prerequisite for differentiation. If this is so, it would follow that replication could continue during early stages of differentiation. An alternative interpretation might be that preadipocytes that showed no discernable lipid accumulation (42-53\% of total cells) formed a subpopulation of dividing cells, while the preadipocytes showing overt signs of differentiation were in a phase of growth arrest and did not replicate. The latter cells may or may not have been terminally differentiated. The proposed existence of subpopulations of preadipocytes in our culture system might be determined by clonal studies. Such variation in subpopulations of preadipocytes with different requirements for differentiation have been reported $(27,28)$. 

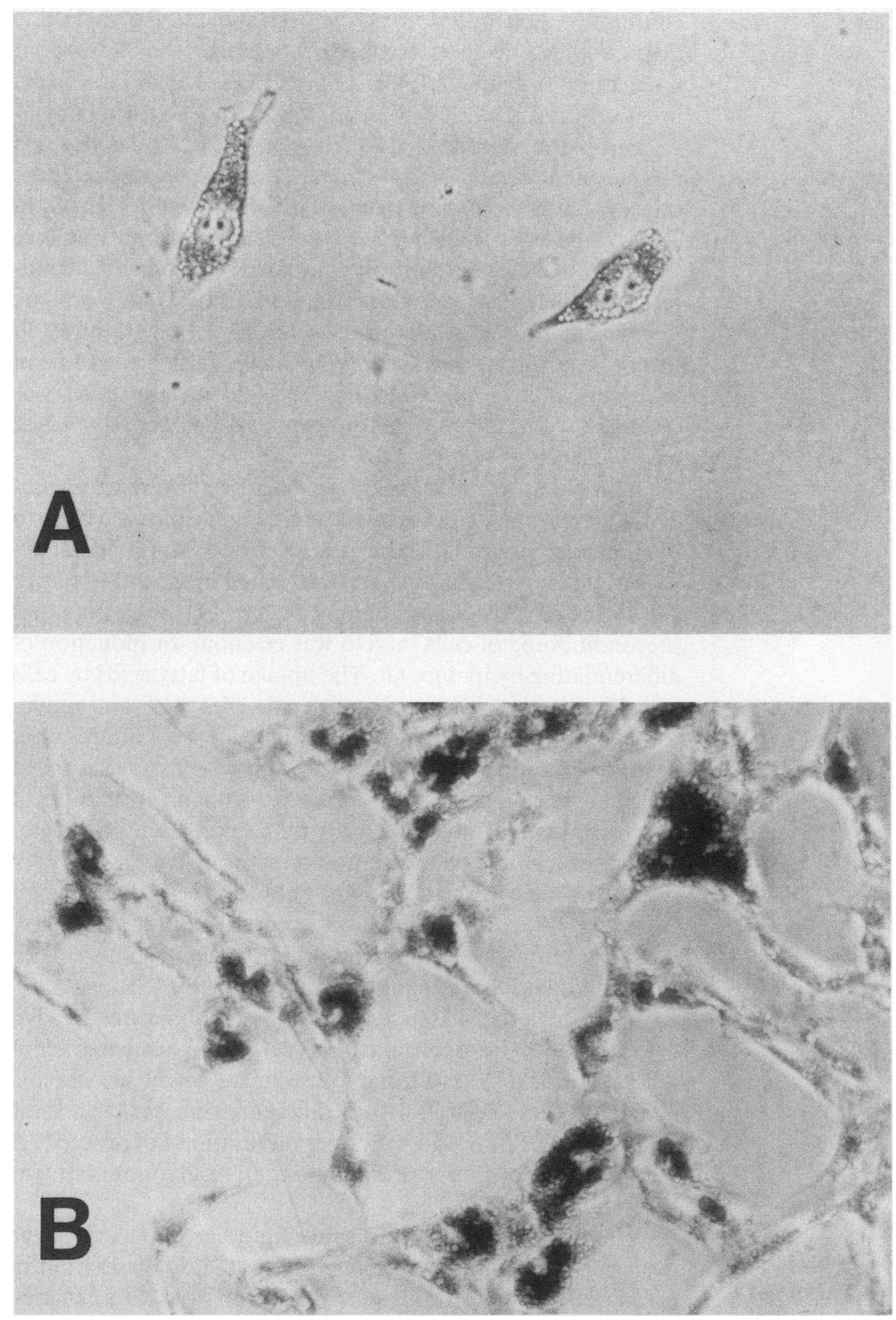

Figure 3. Photomicrographs of preadipocytes derived from the retroperitoneal pad. $(A)$ Dividing cells containing numerous cytoplasmic lipid droplets. These cells were photographed in culture after $5 \mathrm{~d}$ in Alpha MEM supplemented with 1 $\mathrm{mM}$ oleic acid. (B) Substantial cytoplasmic lipid accumulation in cells cocultured with mature fat tissue well before confluence was reached. Cells were fixed and stained with oil red $\mathrm{O}$ and Giemsa. Original magnification, $\times 200$.

The observed differentiation was not contingent upon the prior attainment of confluence by the cells, since in many instances substantial lipid accretion was observed well before confluence was reached (Fig. $3 B$ ). In previously reported studies of rat preadipocytes in primary culture, differentiation was initiated only after confluence was achieved $(18,27)$. Confluence was thought to be a prerequisite for differentiation in 3T3-L1 cells $(1,2,8)$, but adipose conversion has been shown to occur in low density cultures containing high concentrations of human plasma (23).

The induction of differentiation was not a result of cellular contact since lipid accumulation was observed in preadipocytes cocultured with mature fat tissue separated from the preadipocytes by a membrane of $0.4-\mu \mathrm{m}$ pore diameter. Thus, the effect must be attributed to diffusable factors released by the mature fat cells.

The acceleration of differentiation was not due to the presence of free fat released from broken mature fat cells since TG added to the medium failed to significantly increase lipid accretion. The observed differentiation was also probably not due to the addition of insulin and corticosterone to the medium. It could be argued that trace amounts of these hormones or other factors might have been present in the cocultured fat tissue, but it would seem unlikely that hormones, in quantities sufficient to stimulate differentiation, would remain associated with the free mature fat cells in the floating fraction of the collagenase digest. Yet the effect of the isolated adipocytes was not significantly reduced compared with that of the whole tissue incubation. The addition of $10^{-8} \mathrm{M}$ insulin and $10^{-7} \mathrm{M}$ corticosterone (MIX) to the preadipocytes after confluence was reached and incubation for a further $7 \mathrm{~d}$ did not promote a significantly greater induction of GPDH activity than obtained in the cells incubated with mature fat, although the amount of lipid accumulated in the former was considerably more (Fig. 1). The excess lipid accretion with added MIX may have been due to the addition of lipid substrate (intralipid) to 


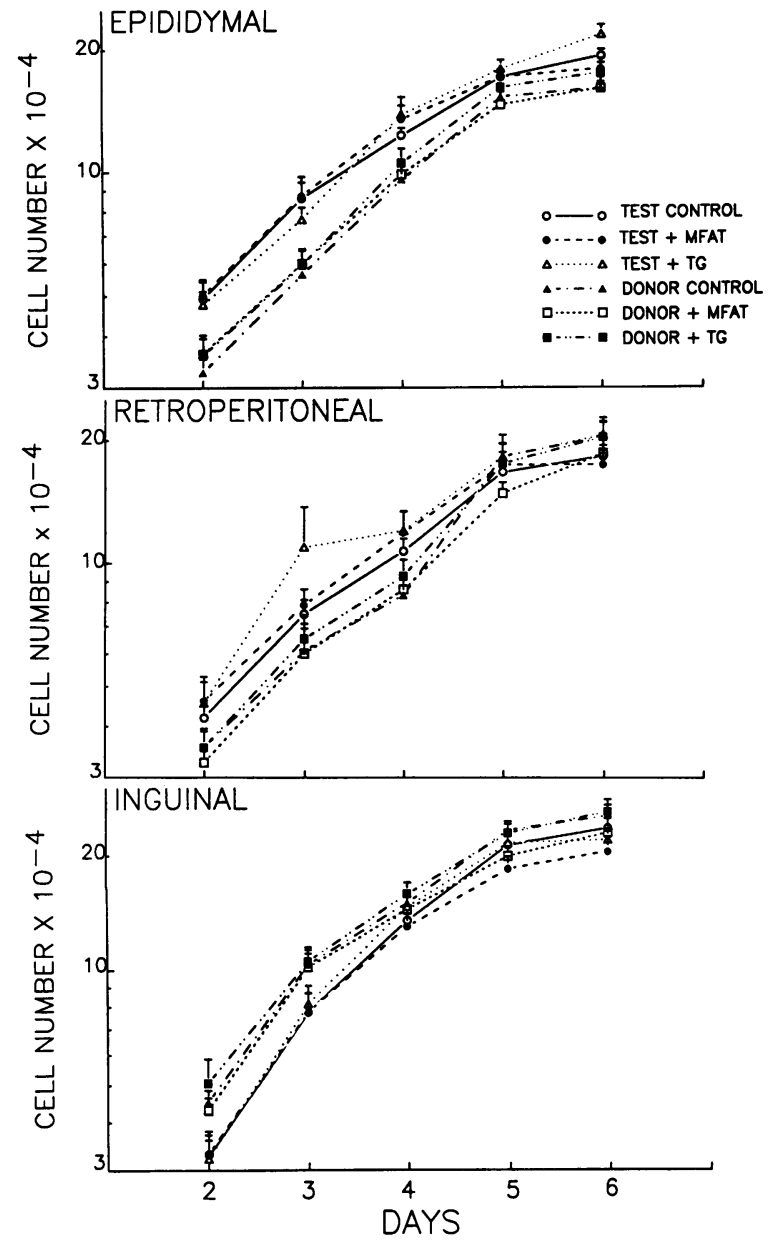

Figure 4. The rate of replication in primary culture of preadipocytes derived from epididymal, retroperitoneal, and inguinal fat pads. Cells derived from both donor and test rats were cultured in Alpha MEM alone (control), or medium with addition of mature fat tissue $(+M F A T)$ or TG $(+T G)$. The population doubling times were not statistically different among the various conditions.

the medium and to the extra $7 \mathrm{~d}$ in culture. The fact that assay of GPDH in cells grown in the presence of mature fat or MIX showed similar activity, despite the longer duration of the latter culture, suggests that preadipocytes cocultured with mature fat reached close to maximal activity of the enzyme for the initial seeding density used. Cell seeding density has been shown to affect the development of GPDH activity in rat preadipocytes (18).

Lactate is a major metabolic product of adipocytes (29). There is also evidence that adipocytes can use lactate for incorporation into fatty acids (30). However, our data did not support a role for lactate in the differentiation of preadipocytes in vitro. When cells were grown in lactate concentrations two- to threefold greater than those produced by cultured preadipocytes and mature fat tissue, no cells could be found containing fat droplets. In fact, the spontaneous differentiation (1-3\%) observed in preadipocytes grown in medium alone appeared to be suppressed by the presence of lactate.

The effect of adipose tissue or isolated mature fat cells on differentiation may have been induced by the release of free fatty acids. The addition of oleic acid to preadipocytes in culture caused almost total differentiation as assessed by the commonly used criterion of the appearance of cytoplasmic lipid droplets, even at a concentration that did not inhibit replication $(0.25 \mathrm{mM})$. Cells exposed to oleic acid resembled, in all respects, the cells differentiating in the presence of insulin and corticosterone (MIX). However, GPDH activity was not elevated in fatty acid-exposed cells and, therefore, these cells cannot be considered to have differentiated. As shown in Table I, the level of GPDH activity of cells in primary culture was slightly elevated (control) compared with cells in subculture (baseline). This small rise in GPDH activity may provide a sufficient source of glycerol via the glycolytic pathway to incorporate with the abundantly available fatty acids to form TG. The addition of $1 \mathrm{mM}$ oleic acid to preadipocytes was cytotoxic within $24 \mathrm{~h}$ of culture when GPDH activity was at baseline levels.

In contrast to the effect of oleic acid, exposure of preadipocytes in primary culture to mature fat tissue induced close to maximal activity of GPDH (Table I). However, GPDH activity was not stimulated by mature fat tissue in second to fourth subculture $(25.3 \pm 5.9 \mathrm{nM} / \mathrm{min}$ per $\mathrm{mg}, n=5)$, suggesting that preconditioning of cells in vivo was essential for induction of differentiating by mature fat. The uptake of fatty acids by cells in culture is known to be a nonspecific effect (19) and might, therefore, be expected to occur equally in subculture as in primary culture. But $1 \mathrm{mM}$ oleic acid was cytotoxic when added to preadipocytes in subculture, with no formation of lipid droplets and no viable cells remaining after 24-h exposure, although this concentration apparently caused lipid accretion in most cells in primary culture. These data suggest that since $100 \%$ of preadipocytes accumulated fat in primary culture when exposed to oleic acid (at concentrations $>0.25$ $\mathrm{mM}$ ), differentiation, manifested by increasing GPDH activity, must have been initiated in most preadipocytes in vivo before isolation from the fat pads. As GPDH is a late marker of differentiation $(11,25)$, lipoprotein lipase might also be expressed in these cells $(8-10)$. If differentiation has been initiated in most cells in vivo, why does maturation not proceed? A local inhibitor of complete differentiation or maturation might be postulated.

We conclude that, while some lipid accretion may have been due to the presence of fatty acids, the differentiation of preadipocytes was stimulated by a factor or factors released into the culture medium by mature adipocytes. Further characterization of this putative paracrine factor is currently being investigated in our laboratory.

\section{Acknowledgments}

This work was supported by grants from the Medical Research Council of Canada (MA-9178), the Alberta Heritage Foundation for Medical Research, and the Canadian Diabetes Association. Dr. G. Shillabeer is a Postdoctoral Fellow of the Alberta Heritage Foundation for Medical Research. Dr. D. C. W. Lau is a Scholar of the Medical Research Council of Canada and the Alberta Heritage Foundation for Medical Research.

\section{References}

1. Green, H., and M. Meuth. 1974. An established preadipose cell line and its differentiation in culture. Cell. 3:127-133.

2. Green, H., and O. Kehinde. 1975. An established preadipocyte cell line and its differentiation in culture. II. Factors affecting adipose conversion. Cell. 5:19-27. 
3. Morikawa, M., H. Green, and U. J. Lewis. 1984. Activity of human growth hormone and related peptides on the adipose conversion of 3T3 cells. Mol. Cell Biol. 4:228-231.

4. Nixon, T., and H. Green. 1985. Contribution of growth hormone to the adipogenic activity of serum. Endocrinology. 114:527532.

5. Smith, P. J., L. S. Wise, R. Berkowitz, C. Wan, and C. S. Rubin. 1988. Insulin-like growth factor-I is an essential regulator of the differentiation of 3T3-L1 adipocyte. J. Biol. Chem. 263:9402-9408.

6. Chapman, A. B., D. M. Knight, and G. M. Ringold. 1985. Glucocorticoid regulation of adipocyte differentiation. Hormonal triggering of the developmental program and induction of a differentiation dependent gene. J. Cell Biol. 101:1227-1235.

7. Guller, S., R. E. Corin, D. C. Mynarcik, B. M. London, and M. Sonenberg. 1987. Role of insulin in growth hormone-stimulated 3T3 cell adipogenesis. Endocrinology. 122:2084-2089.

8. Eckel, R. H., W. Y. Fujimoto, and J. D. Brunzell. 1977. Development of lipoprotein lipase in cultured 3T3-L1 cells. Biochem. Biophys. Res. Commun. 78:288-293.

9. Wise, L. S., and H. Green. 1978. Studies of lipoprotein lipase during the adipose conversion of 3T3 cells. Cell. 13:233-242.

10. Spooner, P. M., S. S. Chernick, M. M. Garrison, and R. O. Scow. 1979. Development of lipoprotein lipase activity and accumulation of triacylglycerol in differentiating 3T3-L1 adipocytes. J. Biol. Chem. 254:1305-1311.

11. Pairault, J., and H. Green. 1979. A study of the adipose conversion of suspended 3T 3 cells by using glycerol phosphate dehydrogenase as a differentiation marker. Proc. Natl. Acad. Sci. USA. 76:51385142 .

12. Löffler, G., and H. Hauner. 1987. Adipose tissue development: the role of precursor cells and adipogenic factors. II. The regulation of the adipogenic conversion by hormones and serum factors. Klin. Wochenschr. 65:812-817.

13. Faust, I. M., P. R. Johnson, J. S. Stern, and J. Hirsch. 1978. Diet induced adipocyte number increase in adult rats: a new model of obesity. Am. J. Physiol. 235:E279-E286.

14. Djian, P., D. A. K. Roncari, and C. H. Hollenberg. 1983. Influence of anatomic site and age on the replication and differentiation of rat adipocyte precursors in culture. J. Clin. Invest. 72:12001208.

15. Lau, D. C. W., K. L. Wong, and S. C. Tough. 1987. Regional differences in the replication rate of cultured rat microvascular endothelium from retroperitoneal and epididymal fat pads. Clin. Exp. Metab. 36:631-636.
16. Lau, D. C. W., and K. L. Wong. 1985. Influence of endothelial cells on the growth of adipocyte precursors in culture. Clin. Invest. Med. 8:A76. (Abstr.)

17. Lau, D. C. W., D. A. K. Roncari, and C. H. Hollenberg. 1987. Release of mitogenic factors by cultured preadipocytes from massively obese human subjects. J. Clin. Invest. 79:632-636.

18. Wiederer, O., and G. Löffler. 1987. Hormonal regulation of the differentiation of rat adipocyte precursor cells in primary culture. $J$. Lipid Res. 28:649-658.

19. Geyer, R. P. 1967. Uptake and retention of fatty acids by tissue culture cells. Wistar Inst. Symp. Monogr. 6:33-47.

20. Wise, L. S., and H. Green. 1979. Participation of one isozyme of cytosolic glycerophosphate dehydrogenase in the adipose conversion of 3T3 cells. J. Biol. Chem. 254:273-275.

21. Spector, T. 1978. Refinement of the Coomassie blue method of protein quantitation. Anal. Biochem. 86:142-146.

22. Marbach, E. P., and M. H. Weil. 1967. Rapid enzymatic measurement of blood lactate and pyruvate. Clin. Chem. 13:314-325.

23. Krawisz, B. R., and R. E. Scott. 1982. Coupling of proadipocyte growth arrest and differentiation. I. By heparinized medium containing human plasma. J. Cell Biol. 94:394-399.

24. Scott, R. E., B. J. Hoerl, J. J. Wille, D. L. Florine, B. R. Krawisz, and K. Yun. 1982. Coupling of proadipocyte growth arrest and differentiation. II. A cell cycle model for the physiological control of cell proliferation. J. Cell Biol. 94:400-405.

25. Amri, E. Z., C. Dani, A. Doglio, P. Grimaldi, and G. Ailhaud. 1986. Coupling of growth arrest and expression of early markers during adipose conversion of preadipocyte cell lines. Biochem. Biophys. Res. Commun. 137:903-910.

26. Weir, M., and R. E. Scott. 1986. Regulation of the terminal event in cellular differentiation: biological mechanisms of the loss of proliferative potential. J. Cell Biol. 102:1955-1964.

27. Gaben-Cogneville, A. M., Y. Aron, G. Idriss, T. Jahchan, J. Y. Pello, and E. Swierczewski. 1983. Differentiation under the control of insulin of rat preadipocytes in primary culture. Biochim. Biophys. Acta. 762:437-444.

28. Djian, P., D. A. K. Roncari, and C. H. Hollenberg. 1985. Adipocyte precursor clones vary in capacity for differentiation. Clin. Exp. Metab. 34:880-883.

29. Thacker, S. V., M. Nickel, and M. DiGirolamo. 1987. Effects of food restriction on lactate production from glucose by rat adipocytes. Am. J. Physiol. 253:E336-E342.

30. Saggerson, E. D., T. W. J. McAllister, and H. S. Baht. 1988. Lipogenesis in rat brown adipocytes. Biochem. J. 251:701-709. 